\title{
The direct and indirect effects of nanotwin volume fraction on the strength and ductility of coarse-grained metals
}

\author{
X. Guo a,b,*, Q.D. Ouyang ${ }^{\mathrm{a}}$, G.J. Weng ${ }^{\mathrm{c}}$, L.L. Zhu ${ }^{\mathrm{d}}$ \\ a School of Mechanical Engineering, Tianjin University, Tianjin 300072, China \\ b Tianjin Key Laboratory of Nonlinear Dynamics and Chaos Control, Tianjin 300072, \\ China \\ ${ }^{\mathrm{c}}$ Department of Mechanical and Aerospace Engineering, Rutgers University, New \\ Brunswick, NJ 08903, USA \\ ${ }^{\mathrm{d}}$ Department of Engineering Mechanics, School of Aeronautics and Astronautics, \\ Zhejiang University, Hangzhou 310027, Zhejiang, China
}

\begin{abstract}
Coarse-grained (CG) metals strengthened by nanotwinned (NT) regions have an excellent combination of high strength and good ductility. In this paper, numerical simulations based on the mechanism-based strain gradient plasticity and the Johnson-Cook failure criterion are carried out to investigate the direct and indirect effects of volume fraction of the NT regions and several other key attributes on the strength and ductility of the CG metal strengthened by NT regions. Our results indicate that twin spacing, shape, distribution, and volume fraction of NT regions all have significant effects, and that, as the volume fraction increases, the roles played by the twin spacing and shape of NT regions also change. At low volume fraction of NT regions, their shape is found to have a significant influence on the overall ductility. As the volume fraction increases, the shape effect on the ductility is found to diminish even though the effect on the strength is noted to continue to enhance. While twin spacing and volume fraction of NT regions have shown different effects on the ductility, the effect of twin spacing always decreases as the volume fraction increases. During the simulations we have also discovered several intrinsic deformation and failure mechanisms through the analysis of microcrack initiation sites and microcrack propagation paths. It is believed that this simulation has revealed significant insights into the roles of volume fraction, twin spacing, shape, and distribution of NT regions on the strength and ductility of this novel class of materials.
\end{abstract}

Keywords: Nanotwin; Volume fraction; Strain gradient plasticity; Johnson-Cook failure criterion; Microstructure; Twin spacing.

\footnotetext{
* Corresponding author.

E-mail address: xiangguo@tju.edu.cn (X. Guo).
} 


\section{Nomenclature}

$A, B, C, m, n$

parameters in the Johnson-Cook plasticity model

$b$

Burgers vector

$d_{1}, d_{2}, d_{3}, d_{4}, d_{5}$

parameters in the Johnson-Cook failure criterion

$d_{\mathrm{G}}$

grain size

$d_{\mathrm{TBDPZ}}$

TBDPZ thickness

$d_{\mathrm{TW}}$

twin spacing

$D$

damage parameter

$f$

$l_{\mathrm{ch}}$

volume fraction of NT regions

characteristic length of NT regions

$k^{\mathrm{GB}}$

pre-factor in Eq. (4)

$m_{0}$

strain-rate sensitivity exponent

$M$

Taylor factor

$n_{\mathrm{F}}^{\mathrm{TB}}$

number of full dislocations in TBDPZ

$n_{\mathrm{P}}^{\mathrm{TB}}$

number of partial dislocations in TBDPZ

$N_{0}$

maximum number of full dislocations in the grain

hydrostatic pressure

temperature

melting temperature

room temperature

Taylor constant

$\gamma^{\mathrm{TB}}$

shear strain associated with dislocations in TBDPZ

$\varepsilon_{\mathrm{e}}^{\mathrm{p}}$

equivalent plastic strain

$\varepsilon_{\mathrm{f}}$

$\dot{\varepsilon}_{0}$

failure strain

reference strain rate

equivalent strain rate

$\dot{\varepsilon}_{\mathrm{e}}^{\mathrm{p}}$

equivalent plastic strain rate 


$\begin{array}{ll}\eta^{\mathrm{GB}} & \text { strain gradient in GBDPZ } \\ \eta^{\mathrm{TB}} & \text { strain gradient in TBDPZ } \\ \mu & \text { shear modulus } \\ \rho_{\mathrm{GB}} & \text { dislocation density in GBDPZ } \\ \rho_{\mathrm{I}} & \text { dislocation density in the grain interior } \\ \rho_{\mathrm{TB}} & \text { dislocation density in TBDPZ } \\ \sigma_{\mathrm{e}} & \text { von Mises stress } \\ \sigma_{\text {flow }} & \text { flow stress } \\ \mathrm{CG} & \text { coarse-grained } \\ \mathrm{DPD} & \text { dynamic plastic deformation } \\ \mathrm{DPZ} & \text { dislocation pileup zones } \\ \mathrm{GB} & \text { grain boundary } \\ \mathrm{GBDPZ} & \text { grain boundary dislocation-pileup-zones } \\ \text { NT } & \text { nanotwinned } \\ \text { TB } & \text { twin boundary } \\ \text { TBDPZ } & \text { twin boundary dislocation-pileup-zones } \\ & \end{array}$




\section{Introduction}

High strength and good ductility is a strong demand for modern metal and alloy manufacturing industry. Therefore, manufacture of materials with high strength and good ductility has consistently been a goal in the fields of mechanics and materials science. Recently, nanostructured (NS) materials have attracted much attention due to their good mechanical properties, and are expected to be widely used in many fields. Over the past decade there has been a surge in the study of NS metals and alloys. Nanocrystallization is generally considered as an effective method for obtaining high strength of materials. This is mainly attributed to the increased resistance to dislocation initiation and propagation with grain size refinement [1]. However, for most NS materials, the increase in strength is always compromised by the decrease in ductility. The decrease in grain size results in a drop of work hardening, and leads to low tensile ductility and plastic instability [2].

A series of methods have been attempted to overcome the limitation of low ductility. Ma [3] summarized eight routes to improve the tensile ductility of bulk NS metals and alloys. Among them, nanotwinned (NT) metals and alloys have attracted considerable attention due to their excellent mechanical properties and high thermal stability [4-7]. NT $\mathrm{Cu}$ with a twin spacing $15 \mathrm{~nm}$ has a high strength of $1 \mathrm{GPa}$ together with a uniform elongation of $8.0 \%$ [4]. Ultrafine-grained $\mathrm{Cu}$ films containing nanoscale growth twins exhibit a strength of $1 \mathrm{GPa}$ with a tensile strain of $13 \%$ [8]. This originates from the fact that twin boundaries (TBs) not only serve as effective barriers to dislocation motion, but also accommodate dislocation storage $[9,10]$. Therefore, metals can keep ductility while be strengthened [8-25].

In recent years a novel combination of metal treatment approach, which is dynamic plastic deformation (DPD) followed by recovery annealing, has been utilized to fabricate coarse-grained (CG) structures strengthened by NT regions. In face-centered cubic metals, twinning can be substantially facilitated at high strain rates. Therefore, the DPD process is preferable for generating nanotwins [26]. The as-DPDed sample is characterized by a mixed nanostructure consisting of NT regions, nanograins, and dislocation structures [26,27]. Subsequent annealing recrystallizes the nanograins and dislocation structures into the coarse grains, while the NT regions remain. Via altering the conditions of DPD and the subsequent annealing, one can obtain different volume fraction of NT regions (for brevity it will be henceforth shortened as volume fraction) [28-32]. As a result, a series of CG metals strengthened 
by NT regions with diverse volume fraction can be fabricated. The composite structure with NT regions embedded in the CG metals has been proven to achieve both ultrahigh strength and good ductility $[9,10,28-33]$.

Experimental observations have significantly contributed to our understanding of NT metals [8-18,20-25,34-39]. However, the exact NT region shape, distribution, and volume fraction, are experimentally difficult to reproduce, and each of these microstructural features can have remarkable effects on property of materials. If these key factors are not accurately analyzed, it will be very difficult to predict the overall mechanical response. Some researchers have performed atomic simulations while others have used theoretical modeling [40-44]. However, they all have not scaled up to the macroscopic level of CG metals strengthened by NT regions.

Our approach here is numerical. In a recent numerical study we have discovered that twin spacing and distribution characteristics of NT regions have significant effects on the strength and ductility of the $\mathrm{CG} \mathrm{Cu}$ strengthened by NT regions [45]. However, the main results we reported were obtained only for a fixed volume fraction of NT regions at $\sim 20 \%$. As a consequence the effects of NT regions over the broad range of volume fraction have not been investigated [45]. As the volume fraction changes, the effects of twin spacing and microstructure on the overall strength and ductility are also likely to change - indirect effects of volume fraction of NT regions may arise from the twin spacing and microstructure. This is the focus of this paper. We intend to systematically analyze the effect of volume fraction on the overall strength and ductility, and how the volume fraction potentially alters the influences of other key factors. In a very recent paper we have also investigated the ballistic performance of CG metals strengthened by NT regions, and found that it has superb bullet-proof capability [46]. This is another novel feature of this class of materials.

In what follows, we will employ the mechanism-based strain gradient plasticity model to describe the constitutive relations of the NT phase, and further expand to the condition of high strain rate via the Johnson-Cook plasticity model. The failure process will be investigated through the Johnson-Cook failure model. We will carry out our analysis over a broad range of volume fraction of NT regions to consider the influences of twin spacing, shape, and distribution of NT regions on the property of CG metals strengthened by NT regions. Our objective is to provide a comprehensive set of knowledge on the effects of these factors through this computer simulations that are otherwise not available. 


\section{Numerical method}

\subsection{Idealized microstructures}

The microstructure with a length $300 \mu \mathrm{m}$ and a width $60 \mu \mathrm{m}$ is studied. In real cases, morphological characteristics of the $\mathrm{CG} \mathrm{Cu}$ strengthened by NT regions are quite complex and the random distribution of NT regions is hard to simulate [28]. Therefore, we simplify the real cases and generate six idealized microstructures, which are shown in Fig. 1 with the CG phase in green and the NT phase in red. The volume fraction of the NT regions, $f$, in the six microstructures is almost the same, while their shape and distribution vary.

For ease of description, we group different microstructures. Series A includes microstructure A (Fig. 1a) with circular NT regions, AR (Fig. 1c) with square NT regions, and AR-45 (Fig. 1e) with oblique square NT regions, which all consist of the array-arranged uniform NT regions. Series B includes microstructure B (Fig. 1b) with circular NT regions, BR (Fig. 1d) with square NT regions, and BR-45 (Fig. 1f) with oblique square NT regions, which all have NT regions with the staggered arrangement. Circular particles series includes microstructures A and B which consist of NT regions with the same circular shape and area but different distribution. We replace each circular region in microstructures $\mathrm{A}$ and $\mathrm{B}$ with a square region at the same sites and of the same area to obtain microstructures $\mathrm{AR}$ and BR, respectively, and they constitute series $\mathrm{R}$. Then we rotate each square region in microstructures AR and BR $45^{\circ}$ to obtain microstructures AR-45 and BR-45, respectively, and they constitute series R-45.

To investigate the influence of volume fraction of NT regions on mechanical property, we change it by controlling the characteristic length $\left(l_{\mathrm{ch}}\right)$ of NT regions, and they are $2,3,4,5,6,7,8,9 \mu \mathrm{m}$, with the corresponding volume fractions, $f, 3.14 \%$, $7.06 \%, 12.56 \%, 19.61 \%, 28.28 \%, 38.50 \%, 50.28 \%, 63.61 \%$, as illustrated in Fig. 2 . The parameter $l_{\mathrm{ch}}$ refers to the radius of a circular NT region in microstructures A and $\mathrm{B}$, and it remains when the shape of a NT region changes. In other words, with the same $l_{\mathrm{ch}}$, the area of a single square NT region in microstructures from series $\mathrm{R}$ or R-45 is equal to that of a single circular NT region in microstructures from circular particles series. Therefore, with the same $l_{\mathrm{ch}}$, the volume fractions of NT regions in the six microstructures (microstructures $\mathrm{A}, \mathrm{B}, \mathrm{AR}, \mathrm{BR}, \mathrm{AR}-45$, and $\mathrm{BR}-45$ ) are all equal. It should be pointed out that, when $l_{\text {ch }}$ is large, adjacent NT regions in some microstructures may contact or even overlap, which is not permitted within the scope 
of this study. Therefore, when $l_{\mathrm{ch}}=8 \mu \mathrm{m}$, microstructure AR-45 does not exist; and when $l_{\mathrm{ch}}=9 \mu \mathrm{m}$, microstructures AR-45 and BR-45 do not exist.

In our simulations, we impose the symmetric velocity boundary conditions $(1 \mathrm{~m}$ $\mathrm{s}^{-1}$ ) along the upper and lower edges of the microstructure. The corresponding overall strain rate is in the order of $10^{4} \mathrm{~s}^{-1}$. Both the left and right edges are traction free. We also impose a room-temperature field $25{ }^{\circ} \mathrm{C}$. To make a balance between computational accuracy and efficiency, we choose linear triangular elements with a characteristic size $0.25 \mu \mathrm{m}$. The number of nodes is $\sim 300 \mathrm{k}$ and that of triangular elements is $\sim 600 \mathrm{k}$. The calculation is under the condition of plane stress. The simulation of dynamic loading process is conducted by ABAQUS/Explicit [47].

\subsection{Constitutive relation of the NT regions}

Each NT region contains ultrafine grains and each ultrafine grain contains a few to more than a hundred twin lamellas [4]. The hierarchical structure of microstructure A with $l_{\mathrm{ch}}=6 \mu \mathrm{m}$ is shown in Fig. 3. The dislocations usually pile up along the TBs and GBs so that the dislocation-pileup-zones (DPZ) near the internal boundaries have significant strain gradients. A constitutive relation with the strain-gradient effects has been derived from the dislocation density-based physical model [48]; its main points are summarized as follow.

The Taylor's model tells that the flow stress can be expressed as [48-50]

$$
\sigma_{\text {flow }}=M \alpha \mu b \sqrt{\rho_{\mathrm{I}}+\rho_{\mathrm{TB}}+\rho_{\mathrm{GB}}},
$$

where $\rho_{\mathrm{I}}$ denotes the dislocation density in the grain interior of the unit cell, $\rho_{\mathrm{TB}}$ denotes that in the TBDPZ, and $\rho_{\mathrm{GB}}$ that in GBDPZ. $M(=3.06), \alpha(=0.33)$, $\mu(=46.3 \mathrm{GPa})$, and $b(=0.256 \mathrm{~nm})$ are the Taylor factor, the Taylor constant, the shear modulus, and the Burgers vector of the face-centered cubic $\mathrm{Cu}$, respectively. The local mean strain gradient in the TBDPZ can be expressed as [48]

$$
\eta^{\mathrm{TB}}=\frac{\gamma^{\mathrm{TB}}}{d_{\mathrm{TBDPZ}}}=\frac{\left(n_{\mathrm{F}}^{\mathrm{TB}}+n_{\mathrm{P}}^{\mathrm{TB}} / \sqrt{3}\right) b}{d_{\mathrm{TBDPZ}} d_{\mathrm{G}}},
$$

where $\gamma^{\mathrm{TB}}$ is the shear strain due to dislocations in the TBDPZ, $d_{\mathrm{TBDPZ}}$ the TBDPZ thickness, $n_{\mathrm{F}}^{\mathrm{TB}}$ the number of full dislocations, $n_{\mathrm{P}}^{\mathrm{TB}}$ the number of partial 
dislocations, and $d_{\mathrm{G}}(=500 \mathrm{~nm})$ the size of the unit cell. The density of full dislocations in the TBDPZ in the unit cell is derived as [48]

$$
\rho_{\mathrm{TB}}=\frac{12 N_{0}}{\pi d_{\mathrm{G}}^{2}}+\frac{12 n_{\mathrm{P}}^{\mathrm{TB}}}{\sqrt{3} \pi d_{\mathrm{G}}} \frac{1}{d_{\mathrm{TW}}}-\frac{\sqrt{3}}{\pi} \frac{1}{d_{\mathrm{TW}}^{2}},
$$

where $N_{0}$ the maximum number of full dislocations in a grain and independent of $d_{\mathrm{TW}}$. The density of dislocations in the GBDPZ, $\rho_{\mathrm{GB}}$, can be related to the local strain gradient in the GBDPZ, $\eta^{\mathrm{GB}}$, as [48]

$$
\rho_{\mathrm{GB}}=k^{\mathrm{GB}} \frac{\eta^{\mathrm{GB}}}{b}
$$

where $k^{\mathrm{GB}}=6 d_{\mathrm{GBDPZ}} / d_{\mathrm{G}}$. The plastic deformation of the ultrafine grains is dominated by intragrain dislocation-mediated interaction. The density of dislocations in the grain interior, $\rho_{\mathrm{I}}$, is taken to obey a law described by Kocks and Mecking's model [51].

The strain rate tensor can be expressed as the sum of elastic and plastic parts. The elastic strain rate is obtained from the stress rate in a linear elastic relation and the plastic strain rate is proportional to the deviatoric stress. The equivalent plastic strain rate, $\dot{\varepsilon}_{\mathrm{e}}^{\mathrm{p}}$, is determined by [50]

$$
\dot{\varepsilon}_{\mathrm{e}}^{\mathrm{p}}=\dot{\varepsilon}_{\mathrm{e}}\left[\frac{\sigma_{\mathrm{e}}}{\sigma_{\text {flow }}}\right]^{m_{0}},
$$

where $\dot{\varepsilon}_{\mathrm{e}}$ is the equivalent strain rate, $\sigma_{\mathrm{e}}$ the von Mises stress, and $m_{0}$ the strain-rate sensitivity exponent.

In the calculations the Young's modulus of both the NT and CG $\mathrm{Cu}$ will be taken as $124 \mathrm{GPa}$ and their Poisson's ratio as 0.34 . This choice is based on the following observations. Lu et al. [17] conducted several nano-indentation tests of the NT Cu with nearly full density and found that its Young's modulus at $120 \mathrm{GPa}$ was very close to the modulus of the $\mathrm{CG} \mathrm{Cu}$. Zhang et al. [52] performed some tensile tests of free-standing $\mathrm{Cu}$ foils and estimated its Young's modulus as $\sim 110 \mathrm{GPa}$. Based on these two sets of data, Qin et al. [21] took its Young's modulus as $120 \mathrm{GPa}$. 
Furthermore, in the analyses of the CG metals strengthened by NT regions, Yan et al. [10] took the NT phase to possess the same elastic property as the host matrix. These studies have motivated us to take the Young's modulus of the NT $\mathrm{Cu}$ as that of the $\mathrm{CG} \mathrm{Cu}$ at $124 \mathrm{GPa}$. In addition, the first principles calculations of Tadmor and Bernstein [53] have suggested the Poisson's ratio of single-crystalline $\mathrm{Cu}$ as 0.317 , which is very close to the CG $\mathrm{Cu}$. This has led us to take the Poisson's ratio of the NT $\mathrm{Cu}$ to be the same as that of the $\mathrm{CG} \mathrm{Cu}$ at 0.34 .

By comparing (i) the predictions of the above dislocation density-based strain gradient model with (ii) the experimental results of the NT Cu with $d_{\mathrm{G}} 500 \mathrm{~nm}$ and multiple $d_{\mathrm{TW}}$ at a low strain rate $\dot{\varepsilon}_{0}\left(1 \mathrm{~s}^{-1}\right)$ and room temperature [4], $d_{\mathrm{GBDPZ}}$ and $d_{\mathrm{TBDPZ}}$ can be calibrated as $3.6 \mathrm{~nm}$, and $\eta^{\mathrm{GB}}, 0.04 \mathrm{~nm}^{-1}[48]$. With these calibrated results, we can obtain the constitutive relations of the NT phase at the reference strain rate $\dot{\varepsilon}_{0}\left(1 \mathrm{~s}^{-1}\right)$ and room temperature.

\subsection{The Johnson-Cook plasticity model and failure criterion}

The specimen subject to dynamic tension is in high strain rates, so the constitutive relations of the NT regions and the CG at the low strain rate in Section 2.2 need to be extended to the case of high strain rates. We use the Johnson-Cook plasticity model [54] to describe their constitutive behaviors at high strain rate, i.e.,

$$
\sigma_{\mathrm{e}}=\left[A+B\left(\varepsilon_{\mathrm{e}}^{\mathrm{p}}\right)^{n}\right]\left[1+C \ln \left(\frac{\dot{\varepsilon}_{\mathrm{e}}^{\mathrm{p}}}{\dot{\varepsilon}_{0}}\right)\right]\left[1-\left(\frac{T-T_{\mathrm{r}}}{T_{\mathrm{m}}-T_{\mathrm{r}}}\right)^{m}\right] \quad\left(T_{\mathrm{r}} \leq T \leq T_{\mathrm{m}}\right),
$$

where $A, B, C(=0.05$ for the NT $\mathrm{Cu}$ and $=0.025$ for the $\mathrm{CG} \mathrm{Cu}), m(=1.09)$, and $n$ are parameters, $\varepsilon_{\mathrm{e}}^{\mathrm{p}}$ is the equivalent plastic strain, $\dot{\varepsilon}_{0}$ the reference strain rate (taken as $\left.1 \mathrm{~s}^{-1}\right), \quad T$ the temperature, $T_{\mathrm{r}}$ the room temperature, and $T_{\mathrm{m}}$ the melting temperature $\left(1083^{\circ} \mathrm{C}\right)$. A relation $\sigma_{\mathrm{e}}\left(\dot{\varepsilon}_{\mathrm{e}}^{\mathrm{p}}=\dot{\varepsilon}_{0}, T=T_{\mathrm{r}}\right)=A+B\left(\varepsilon_{\mathrm{e}}^{\mathrm{p}}\right)^{n}$ can be used to fit the constitutive relations in Section 2.2. The fitting results, constitutive parameters of each phase in the CG Cu strengthened by NT regions, are tabulated in Ref. [45].

Johnson-Cook failure criterion [55] is employed to express the damage parameter $D$ as a function of the equivalent plastic strain increment $\mathrm{d} \varepsilon_{\mathrm{e}}^{\mathrm{p}}$, i.e.,

$$
D=\int \frac{1}{\varepsilon_{\mathrm{f}}} \mathrm{d} \varepsilon_{\mathrm{e}}^{\mathrm{p}}
$$


where $\varepsilon_{\mathrm{f}}$ is the failure strain and defined by [55]

$$
\varepsilon_{\mathrm{f}}=\left[d_{1}+d_{2} e^{d_{3} \frac{p}{\sigma_{\mathrm{e}}}}\right]\left[1+d_{4} \ln \left(\frac{\dot{\varepsilon}_{\mathrm{e}}^{\mathrm{p}}}{\dot{\varepsilon}_{0}}\right)\right]\left[1+d_{5} \frac{T-T_{\mathrm{r}}}{T_{\mathrm{m}}-T_{\mathrm{r}}}\right] .
$$

Here, $d_{1}$ to $d_{5}$ are material constants and $p$ is hydrostatic pressure. $d_{2}=d_{3}=0$ is a good approximation since loading state does not change too abruptly during deformation [56]. Parameter $d_{1}$ can be directly extracted from the experimental measurements [4]. Here, $d_{4}$ is taken as 0.014 and $d_{5}$ as 1.12 for both the CG and $\mathrm{NT} \mathrm{Cu}$. The high strain-rate deformation is assumed to be adiabatic.

\section{Results and discussion}

We use the six microstructures in Fig. 1 and constitutive parameters into our numerical scheme to find the direct influences of volume fraction and the indirect influences arising from microstructure (shape and distribution) and twin spacing $(4,8$, $10,15,35$, and $96 \mathrm{~nm})$ of $\mathrm{NT} \mathrm{Cu}$ on the overall strength and ductility. In our investigation, since NT regions have higher yield stress and lower failure strain relative to the CG matrix, failure of the material is always initiated by interfacial debonding between the two phases. As debonding proceeds, microcracks propagate in the CG matrix via the coalescence and minor deflection.

\subsection{Direct effects of the volume fraction of NT regions at fixed twin spacing and} microstructure

The volume fraction of NT regions has significant influences on the strength and ductility of the CG metals strengthened by NT regions. In general the stress-strain curve of a material can be best used to quantify its strength and ductility [57-59]. Fig. 4 illustrates the engineering stress-strain curves for microstructures A and AR with different $f$ (and thus different $l_{\mathrm{ch}}$ ) when $d_{\mathrm{TW}}=4 \mathrm{~nm}$. It can be found that as $f$ increases, the ductility decreases monotonically, while the nominal strength continues to increase. The same trend can also be observed for all microstructures with different volume fraction and twin spacing of NT regions. Our simulated results are in a good agreement with the experimental reports of Qin et al. [21] and Yan et al. [31]. Strength and ductility of a structural material are two contradicting features and are in general difficult to improve simultaneously, as the increase of one is always accompanied by decrease of the other to a certain degree. Our study on the CG metals strengthened by NT regions has also reflected a similar trend. This mutually exclusive nature of 
strength and ductility also exists in other advanced materials such as bulk metallic glasses [60-62]. For a specific engineering problem, one often needs to make a trade-off between strength and ductility to meet the actual needs.

While the engineering stress-strain curves are easier to calibrate, they are not the true reflection of the material behavior. Instead, true stress-strain curves are better suited for this purpose. Fig. 5 shows the true stress-strain curves for microstructures $\mathrm{A}$ and AR with different $f$ when $d_{\mathrm{TW}}=4 \mathrm{~nm}$. It can be seen that as $f$ increases, the peak true stress decreases first and then increases. This is distinctly different from the engineering stress-strain curves as shown in Fig. 4. The same trend also exists for the other microstructures. We also note that the overall ductility decreases monotonically in all cases. This analysis indicates that, after reaching the yield limit, different volume fraction would lead to significantly different true stress-strain curves. It also indicates that the resistance of the material to deformation becomes weaker initially and then stronger as the volume fraction increases. This is a non-trivial effect of volume fraction of NT regions on the specific two-phase materials studied here.

\subsection{Indirect effects of the volume fraction of NT regions arising from twin spacing}

In order to study the effect of twin spacing of NT regions, we illustrate the engineering stress-strain curves for different microstructures and volume fraction with various twin spacing. Fig. 6 illustrates some of them. Interestingly, microstructure A is not sensitive to the twin spacing, while microstructure AR is on the opposite. Specifically, with any volume fraction, both strength and ductility of microstructure A with different twin spacing almost coincide. But for microstructure AR, different twin spacing can lead to significant variations in ductility - it decreases monotonically with the increase of twin spacing. In addition, we can also see from Fig. 6 that, as the volume fraction increases, the results with different twin spacing get closer - the influence of twin spacing becomes weaker. We also find that microstructures AR-45, B, and BR-45 are not sensitive to twin spacing, while microstructure BR is similar to microstructure AR.

Furthermore, we notice that when $f<19.61 \%$, microstructure AR with $d_{\mathrm{TW}}=35$ or $96 \mathrm{~nm}$ is significantly less ductile than that with $d_{\mathrm{TW}}<35 \mathrm{~nm}$. To clarify this phenomenon, we output the damage dissipation versus boundary displacement. Fig. 7 shows some of them. It is noted that, at $d_{\mathrm{Tw}}=35$ or $96 \mathrm{~nm}$, damage initiates earlier at lower volume fraction. We also check the corresponding von Mises stress 
distributions and find severe stress concentration around the vertices of square NT regions. The initiation of microcracks in microstructures with $d_{\mathrm{Tw}}=35$ or $96 \mathrm{~nm}$ is much earlier. The conditions that lead to an earlier microcrack initiation are low volume fraction and large twin spacing of NT regions. The combination of the above conditions can cause severe stress concentration at the vertices in microstructures AR and BR. This in turn will accelerate the failure process.

\subsection{Indirect effects of the volume fraction of NT regions arising from microstructure}

In order to investigate the effects of microstructure, we first calculate the engineering stress-strain relations for all microstructures with different volume fraction and twin spacing of NT regions. Fig. 8 illustrates some of them. As the volume fraction increases, the strength of six microstructures increases and scatters, while ductility decreases monotonically and gets closer. Therefore, the effect of microstructure is weakened on ductility while enhanced on strength.

In terms of strength, we find that at each volume fraction, the distinction is small among the microstructures with all twin spacing of NT regions. But as the volume fraction increases, microstructures $\mathrm{AR}$ and $\mathrm{BR}$ are stronger than the others. It also demonstrates that the microstructures in series $\mathrm{R}$ have better strengthening effect at high volume fraction. In terms of ductility, microstructure AR is the best with small twin spacing and low volume fraction $\left(l_{\mathrm{ch}}=2 \mu \mathrm{m}\right.$ and $d_{\mathrm{TW}}=4-15 \mathrm{~nm} ; l_{\mathrm{ch}}=3 \mu \mathrm{m}$ and $d_{\mathrm{TW}}=4 \mathrm{~nm}$ ). As the twin spacing and the volume fraction increase, the ductility of the microstructures from series $\mathrm{R}$ decreases significantly and becomes the worst when $l_{\mathrm{ch}}>3 \mu \mathrm{m}$ and $d_{\mathrm{TW}}>8 \mathrm{~nm}$. More importantly, the ductility of microstructure AR-45 is always the best, except for the cases of $l_{\mathrm{ch}}=2 \mu \mathrm{m}$ together with the case of $l_{\mathrm{ch}}=3 \mu \mathrm{m}$ and $d_{\mathrm{TW}}=4 \mathrm{~nm}$. As the volume fraction increases, its ductility becomes more outstanding. This shows that it has better toughening effect at high volume fraction. (Note that microstructure AR-45 does not exist when $l_{\mathrm{ch}}>7 \mu \mathrm{m}$.)

We further explore the influences of distribution of microstructures. Microstructures A and B have different distribution of circular NT regions. Our analysis shows that microstructure $\mathrm{A}$ is always more ductile than microstructure $\mathrm{B}$, which shows that the array arrangement exhibits better performance in ductility. We find the same trend in series R and R-45. In general, series A with the array arrangement of NT regions is better than series B with the staggered arrangement of NT regions in terms of ductility. 


\subsection{Systematic analysis of series A over a diverse range of volume fraction of NT}

regions

Since series $\mathrm{A}$ is more ductile than series $\mathrm{B}$, we further analyze series $\mathrm{A}$. As for strength, the distinction is small among different microstructures no matter what the volume fraction and the twin spacing is. However, as for ductility, the relation among microstructures A, AR, and AR-45 is pretty complicated. Table 1 illustrates their ductility comparison with different twin spacing and volume fraction of NT regions. In Table 1, “A”, "R", and “45" represent microstructures A, AR, and AR-45, respectively. We also mark the abnormal results. It can be seen that the comparison results are " $45>A>R$ " in most cases. Only in the marginal cases, changes the relative relation. Microstructure AR is the most interesting. In Table 1 , when $l_{\mathrm{ch}}=2 \mu \mathrm{m}$ (the first row in Table 1), with the increase of twin spacing, its relative ductility becomes the worst from the best. When $d_{\mathrm{TW}}=4 \mathrm{~nm}$ (the first column in Table 1), as the volume fraction increases, its relative ductility becomes the worst from the best and then gets better. If we only check the last four rows in Table 1 , it can be found that as $I_{\text {ch }}$ increases, the ductility of microstructure AR surpasses that of microstructure A gradually, and then is the best. To find out the intrinsic mechanisms behind the above observations, we investigate the simulation results further.

First, for microstructure AR with $l_{\mathrm{ch}}=2 \mu \mathrm{m}$, we analyze the corresponding von Mises stress distributions when the microcracks are initiated. Fig. 9 presents some of them. We find that with the increase of twin spacing, the number of the microcrack initiation sites increases gradually. When $d_{\mathrm{TW}}=4 \mathrm{~nm}$, the microcracks are initiated at only several vertices of NT regions. However, when $d_{\mathrm{TW}}=35 \mathrm{~nm}$, the microcracks are initiated at almost every interface, which leads to their earlier failure because of the easy propagation and coalescence of microcracks. Therefore, with the increase of twin spacing, the ductility of the microstructure AR decreases gradually. Meanwhile, as mentioned in Section 3.2, when $d_{\mathrm{TW}}=35$ or $96 \mathrm{~nm}$ and the volume fraction isn't high, the damage initiates earlier. The combination of the two effects facilitates the decrease of the ductility, as showed in Fig. 6b. For the other four microstructures, with the increase of twin spacing, the number of the microcrack initiation sites doesn't increase remarkably.

Next, for microstructure AR with $d_{\mathrm{TW}}=4 \mathrm{~nm}$, we analyze the corresponding von Mises stress distributions when the microcracks are initiated. We find that multiple 
factors have combined effects on the ductility. The main investigations are as follows. (i) Fig. 10 illustrates microcrack propagation paths in microstructure AR with $l_{\mathrm{ch}}=4$ and $8 \mu \mathrm{m}$ when $d_{\mathrm{TW}}=8 \mathrm{~nm}$. As the volume fraction increases, the spacing between the adjacent NT regions becomes narrower, and thus microcrack propagation is more constrained and less sinuous. With low volume fraction, the microcrack can penetrate multiple rows of NT regions and fluctuate significantly, as shown in Fig. 10a. But with high volume fraction, the microcrack can penetrate at most one row of NT regions and fluctuate slightly, as shown in Fig. 10b. Comparatively straight microcrack path will dissipate less energy, resulting in a decrease in ductility. (ii) The increase of the volume fraction can enlarge the debonding regions. In cases of low volume fraction, the microcracks are initiated at several separate points and gradually propagate into strips. However, with high volume fraction, once the microcracks are initiated, they are in strips and thus large debonding regions appear, which accelerates the failure process. In general, as the volume fraction increases, these two factors have different effects on the three microstructures and cause the relative ductility of microstructure AR to fluctuate dramatically, as shown in Table 1.

Finally, we analyze the reversal of the relative ductility of microstructure AR in the last four rows of Table 1 and find two mechanisms. First, with high volume fraction, the number of the microcrack initiation sites in microstructure AR does not change prominently with the increase of twin spacing. When $d_{\mathrm{Tw}}=4 \mathrm{~nm}$, the number has already reached a high level. This leads to a fact that the ductility decrease of microstructure AR is not as dramatic as that when $l_{\mathrm{ch}}=2 \mu \mathrm{m}$. Secondly, when the volume fraction is high, with $d_{\mathrm{TW}}=35$ and $96 \mathrm{~nm}$, the phenomenon of earlier initiation of microcracks almost disappears, and the process from the initiation to totally failure is very fast. Therefore, the earlier initiation of microcracks has a slight influence on the ductility of microstructure AR with high twin spacing and volume fraction. As the volume fraction increases, these two factors mitigate the decrease in the ductility of microstructure AR, which helps the ductility of microstructure AR exceed that of microstructure A.

\section{Conclusion}

The direct and indirect dependences of strength and ductility on the volume fraction of the NT regions are important for the CG metals strengthened by NT regions as it is experimentally controllable and provides an important strengthening mechanism. 
In this paper, the systematic numerical simulations have been carried on via the mechanism-based strain gradient plasticity and the Johnson-Cook failure criterion. It is found that as the volume fraction increases, the nominal strength increases while the ductility decreases monotonically; and the peak true stress decreases first and then increases. The indirect effects of the volume fraction of NT regions can be summarized as follows.

1. The increase of volume fraction will undermine the effect of twin spacing on the overall ductility.

2. With low volume fraction of NT regions, the shape of NT regions has significant influence on the ductility. As the volume fraction increases, the shape effect is weakened on ductility while enhanced on strength.

3. In most cases, the microstructure with array-arranged oblique square NT regions (microstructure AR-45) has the best ductility.

4. The microstructures in series A which consists of array-arranged uniform NT regions is more ductile than those in series $\mathrm{B}$ which has a staggered arrangement of uniform NT regions.

Over a broad range of volume fraction of NT regions, this study provides a panoramic view of the complicated effects of twin spacing, shape, and distribution of NT regions on the strength and ductility of CG metals strengthened by NT regions. They could serve as the guidelines for the design and fabrication of metals and alloys with both good strength and high ductility.

\section{Acknowledgments}

We wish to thank an anonymous reviewer for his/her helpful comments. X. Guo acknowledges the support from National Natural Science Foundation of China (Project nos. 11372214 and 11102128) and Elite Scholar Program of Tianjin University. G.J. Weng thanks the support of NSF Mechanics of Materials and Structures Program under CMMI-1162431. L.L. Zhu acknowledges the support from National Natural Science Foundation of China (Project nos. 11302189 and 11472243). 


\section{References}

[1] R. Valiev, Nature 419 (2002) 887-889.

[2] T.S. Wang, F.C. Zhang, M. Zhang, Mater. Sci. Eng. A 485 (2008) 456-460.

[3] E. Ma, JOM 58(4) (2006) 49-53.

[4] L. Lu, X. Chen, X. Huang, K. Lu, Science 323 (2009) 607-610.

[5] K. Lu, L. Lu, S. Suresh, Science 324 (2009) 349-352.

[6] X. Zhang, A. Misra, H. Wang, T.D. Shen, M. Nastasi, T.E. Mitchell, J.P. Hirth, R.G. Hoagland, J.D. Embury, Acta Mater. 52 (2004) 995-1002.

[7] B.Y.C. Wu, P.J. Ferreira, C.A. Schuh, Metall. Mater. Trans. A 36A (2005) 1927-1936.

[8] Y.F. Shen, L. Lu, Q.H. Lu, Z.H. Jin, K. Lu, Scr. Mater. 52 (2005) 989-994.

[9] F.K. Yan, N.R. Tao, K. Lu, Scr. Mater. 84-85 (2014) 31-34.

[10] F.K. Yan, N.R. Tao, F. Archie, I. Gutierrez-Urrutia, D. Raabe, K. Lu, Acta Mater. 81 (2014) 487-500.

[11] M. Dao, L. Lu, R. Asaro, J.D. Hosson, E. Ma, Acta Mater. 55 (2007) 4041-4065.

[12] Q.Y. Sun, Z.T. Yu, R.H. Zhu, H.C. Gu, Mater. Sci. Eng. A 364 (2004) 159-165.

[13] E. Ma, Y.M. Wang, Q.H. Lu, M.L. Sui, L. Lu, K. Lu, Appl. Phys. Lett. 85 (2004) 4932-4934.

[14] M. Sennour, S.L. Korinek, Y. Champion, M.J. Hytch, Philos. Mag. 87 (2007) 1465-1486.

[15] A.M. Hodge, Y.M. Wang, T.W. Barbee Jr, Mater. Sci. Eng. A 429 (2006) 272276.

[16] L. Lu, Y.F. Shen, X.H. Chen, L.H. Qian, K. Lu, Science 304 (2004) 422-426.

[17] L. Lu, R. Schwaiger, Z.W. Shan, M. Dao, K. Lu, S. Suresh, Acta Mater. 53 (2005) 2169-2179.

[18] Y.F. Shen, L. Lu, M. Dao, S. Suresh, Scr. Mater. 55 (2006) 319-322.

[19] A. Jerusalem, M. Dao, S. Suresh, R. Radovitzky, Acta Mater. 56 (2008) $4647-4657$.

[20] Z.W. Shan, L. Lu, A.M. Minor, E.A. Stach, S.X. Mao, JOM 60(9) (2008) 71-74.

[21] E.W. Qin, L. Lu, N.R. Tao, J. Tan, K. Lu, Acta Mater. 57 (2009) 6215-6225.

[22] E.W. Qin, L. Lu, N.R. Tao, K. Lu, Scr. Mater. 60 (2009) 539-542.

[23] G. Wang, Z. Jiang, J. Lian, Int. J. Modern Phys. B 24 (2010) 2537-2542.

[24] A. Singh, L. Tang, M. Dao, L. Lu, S. Suresh, Acta Mater. 59 (2011) 2437-2446.

[25] B. Roy, R. Kumar, J. Das, Mater. Sci. Eng. A 631 (2015) 241-247. 
[26] Y.S. Li, N.R. Tao, K. Lu, Acta Mater. 56 (2008) 230-241.

[27] Y. Zhang, N.R. Tao, K. Lu, Acta Mater. 56 (2008) 2429-2440.

[28] Y.S. Li, Y. Zhang, N.R. Tao, K. Lu, Scr. Mater. 59 (2008) 475-478.

[29] G.H. Xiao, N.R. Tao, K. Lu, Scr. Mater. 65 (2011) 119-122.

[30] K. Lu, F.K. Yan, H.T. Wang, N.R. Tao, Scr. Mater. 66 (2012) 878-883.

[31] F.K. Yan, G.Z. Liu, N.R. Tao, K. Lu, Acta Mater. 60 (2012) 1059-1071.

[32] H.T. Wang, N.R. Tao, K. Lu, Acta Mater. 60 (2012) 4027-4040.

[33] G.Z. Liu, N.R. Tao, K. Lu K, J. Mater. Sci. Technol. 26 (2010) 289-292.

[34] Y.C. Xin, M.Y. Wang, Z. Zeng, M.G. Nie, Q. Liu, Scripta Mater. 66 (2012) $25-28$.

[35] D.K. Xu, E.H. Han, Scripta Mater. 69 (2013) 702-705.

[36] Y.B. Xu, D.K. Xu, X.H. Shao, E.H. Han, Acta Metall. Sin. 26 (2013) 217-231.

[37] Y.C. Xin, X.J. Zhou, L.C. Lv, Q. Liu, Mater. Sci. Eng. A 606 (2014) 81-91.

[38] D.K. Xu, C.Q. Li, B.J. Wang, E.H. Han, Mater. Des. 88 (2015) 88-97.

[39] Y.C. Xin, H. Zhou, G.L. Wu, H.H. Yu, A. Chapuis, Q. Liu, Mater. Sci. Eng. A 639 (2015) 534-539.

[40] T. Zhu, J. Li, A. Samanta, H.G. Kim, S. Suresh, Proc. Natl. Acad. Sci. 104 (2007) 3031-3036.

[41] H. Zhou, S. Qu, W. Yang, Modelling Simul. Mater. Sci. Eng. 18 (2010) 065002.

[42] L.G. Sun, X.Q. He, J.B. Wang, J. Lu, Mater. Sci. Eng. A 606 (2014) 334-345.

[43] M. Dao, L. Lu, Y.F. Shen, S. Suresh, Acta Mater. 54 (2006) 5421-5432.

[44] B. Wu, Y. Wei, Acta Mech. Solida Sinica 21 (2008) 189-197.

[45] X. Guo, R. Ji, G.J. Weng, L.L. Zhu, J. Lu, Modelling Simul. Mater. Sci. Eng. 22 (2014) 075014.

[46] G. Yang, X. Guo, G.J. Weng, L.L. Zhu, R. Ji, Modelling Simul. Mater. Sci. Eng. 23 (2015) 085009.

[47] ABAQUS/Explicit. ABAQUS Theory Manual and User's Manual, version 6.10. Dassault, Providence, RI, 2013.

[48] L.L. Zhu, H.H. Ruan, X.Y. Li, M. Dao, H.J. Gao, J. Lu, Acta Mater. 59 (2011) 5544-5557.

[49] H. Gao, Y. Huang, W.D. Nix, J.W. Hutchinson, J. Mech. Phys. Solids 47 (1999) 1239-1263.

[50] Y. Huang, S. Qu, K.C. Hwang, M. Li, H.J. Gao, Int. J. Plast. 20 (2004) 753-782.

[51] U.F. Kocks, H. Mecking, Prog. Mater. Sci. 48 (2003) 171-273. 
[52] X. Zhang, H. Wang, X.H. Chen, L. Lu, K. Lu, R.G. Hoagland, A. Misra, Appl. Phys. Lett. 88 (2006) 173116.

[53] E.B. Tadmor, N. Bernstein, J. Mech. Phys. Solids 52 (2004) 2507-2519.

[54] G.R. Johnson, W.H. Cook, In: Proceedings of the 7th International Symposium on Ballistics, The Hague, The Netherlands, 1983.

[55] G.R. Johnson, W.H. Cook, Eng. Fract. Mech. 21 (1985) 31-48.

[56] W. Dabboussi, J.A. Nemes, Int. J. Mech. Sci. 47 (2005) 1282-1299.

[57] X. Guo, A.Y.T. Leung, A.Y. Chen, H.H. Ruan, J. Lu, Scr. Mater. 63 (2010) 403-406.

[58] X. Guo, G.J. Weng, A.K. Soh, Comput. Mater. Sci. 55 (2012) 350-355.

[59] X. Guo, W.J. Zhang, L.L. Zhu, J. Lu, Eng. Fract. Mech. 105 (2013) 211-220.

[60] P. Yu, K.C. Chan, W. Chen, L. Xia, Phil. Mag. Lett. 91 (2011) 70-77.

[61] P. Yu, K.C. Chan, W. Chen, L. Xia, J. Alloy. Compds. 509 (2011) 8518-8521.

[62] S.F. Guo, J.L. Qiu, P. Yu, S.H. Xie, W. Chen, Appl. Phys. Lett. 105 (2014) 161901. 


\section{Captions:}

Fig. 1. Six idealized microstructures.

Fig. 2. Volume fraction versus the characteristic length of NT regions. Microstructure A with three typical volume fraction $(3.14 \%, 19.61 \%$, and $50.28 \%)$ are also shown.

Fig. 3. Hierarchical structure of $\mathrm{CG} \mathrm{Cu}$ strengthened by NT regions.

Fig. 4. Engineering stress versus engineering strain for (a) microstructure A and (b) microstructure AR when $d_{\mathrm{TW}}=4 \mathrm{~nm}$.

Fig. 5. True stress versus true strain for (a) microstructure A and (b) microstructure AR when $d_{\mathrm{TW}}=4 \mathrm{~nm}$.

Fig. 6. Engineering stress versus engineering strain,
(a) microstructure $\mathrm{A}, l_{\mathrm{ch}}=2 \mu \mathrm{m}$, (b) microstructure AR, $l_{\mathrm{ch}}=2 \mu \mathrm{m}$,
(c) microstructure $\mathrm{A}, l_{\mathrm{ch}}=5 \mu \mathrm{m}$, (d) microstructure $\mathrm{AR}, l_{\mathrm{ch}}=5 \mu \mathrm{m}$,
(e) microstructure A, $l_{\mathrm{ch}}=8 \mu \mathrm{m}$, (f) microstructure AR, $l_{\mathrm{ch}}=8 \mu \mathrm{m}$.

Fig. 7. Damage dissipation versus displacement for microstructure AR with (a) $l_{\mathrm{ch}}=2$ $\mu \mathrm{m}$ and (b) $l_{\mathrm{ch}}=4 \mu \mathrm{m}$.

Fig. 8. Engineering stress versus engineering strain for all microstructures with $d_{\mathrm{TW}}=4$ $\mathrm{nm}$ and (a) $l_{\mathrm{ch}}=3 \mu \mathrm{m}$, (b) $l_{\mathrm{ch}}=4 \mu \mathrm{m}$, (c) $l_{\mathrm{ch}}=6 \mu \mathrm{m}$, and (d) $l_{\mathrm{ch}}=7 \mu \mathrm{m}$.

Fig. 9. von Mises stress distributions when the microcracks are initiated in microstructure AR with (a) $d_{\mathrm{Tw}}=4 \mathrm{~nm}$, (b) $d_{\mathrm{TW}}=15 \mathrm{~nm}$, and (c) $d_{\mathrm{Tw}}=96 \mathrm{~nm}$ when $l_{\text {ch }}=2 \mu \mathrm{m}$ (stress is in $\left.\mathrm{Pa}\right)$.

Fig. 10. von Mises stress distributions in microstructure AR with (a) $l_{\mathrm{ch}}=4 \mu \mathrm{m}$ and (b) $l_{\mathrm{ch}}=8 \mu \mathrm{m}$ when $d_{\mathrm{TW}}=8 \mathrm{~nm}$ (stress is in $\left.\mathrm{Pa}\right)$. 


\section{Table 1}

Ductility comparison of the microstructures from series A.

\begin{tabular}{|c|c|c|c|c|c|c|}
\hline & $d_{\mathrm{TW}}=4 \mathrm{~nm}$ & $8 \mathrm{~nm}$ & $10 \mathrm{~nm}$ & $15 \mathrm{~nm}$ & $35 \mathrm{~nm}$ & $96 \mathrm{~nm}$ \\
\hline$I_{\mathrm{ch}}=2 \mu \mathrm{m}$ & $R>A>45$ & $R>A>45$ & $R>A>45$ & $R>A>45$ & $A>R>45$ & $A>45>R$ \\
\hline $3 \mu \mathrm{m}$ & $R>45>A$ & $45>A>R$ & $45>A>R$ & $45>A>R$ & $45>A>R$ & $45>A>R$ \\
\hline $4 \mu \mathrm{m}$ & $45>R>A$ & $45>A>R$ & $45>A>R$ & $45>A>R$ & $45>A>R$ & $45>A>R$ \\
\hline $5 \mu \mathrm{m}$ & $45>R>A$ & $45>A>R$ & $45>A>R$ & $45>A>R$ & $45>A>R$ & $45>A>R$ \\
\hline $6 \mu \mathrm{m}$ & $45>A>R$ & $45>A>R$ & $45>A>R$ & $45>A>R$ & $45>A>R$ & $45>A>R$ \\
\hline $7 \mu \mathrm{m}$ & $45>R>A$ & $45>A>R$ & $45>A>R$ & $45>A>R$ & $45>A>R$ & $45>A>R$ \\
\hline $8 \mu \mathrm{m}$ & $R>A$ & $R>A$ & $A>R$ & $A>R$ & $A>R$ & $A>R$ \\
\hline $9 \mu \mathrm{m}$ & $R>A$ & $R>A$ & $R>A$ & $R>A$ & $R>A$ & $R>A$ \\
\hline
\end{tabular}




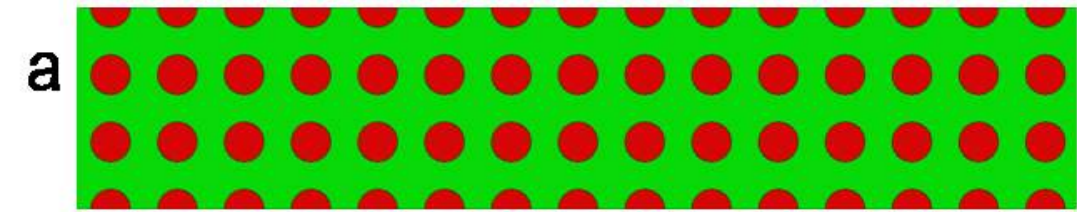

$\mathrm{b} 00000000000000$ 0000000000000

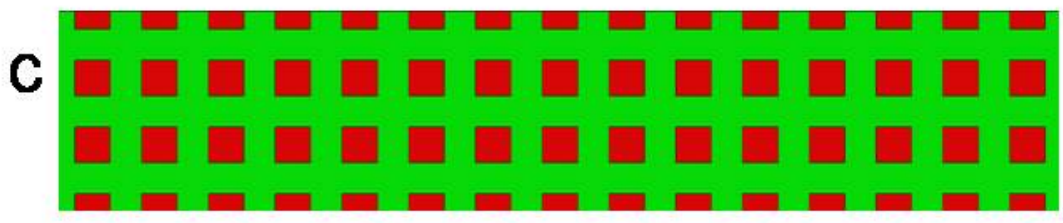
Q

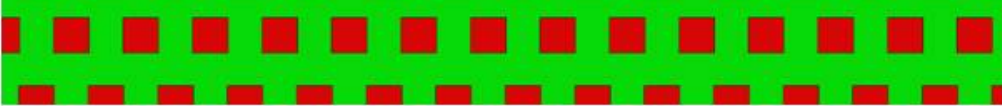

e

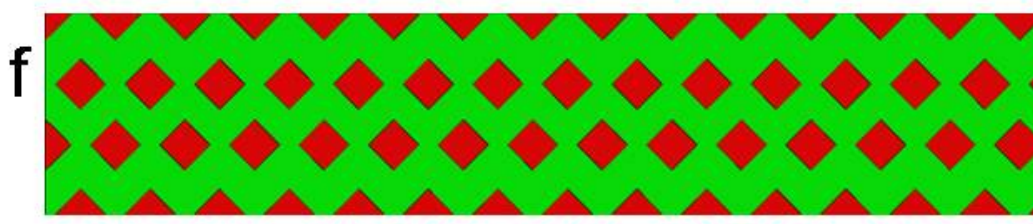

\section{Fig. 1}



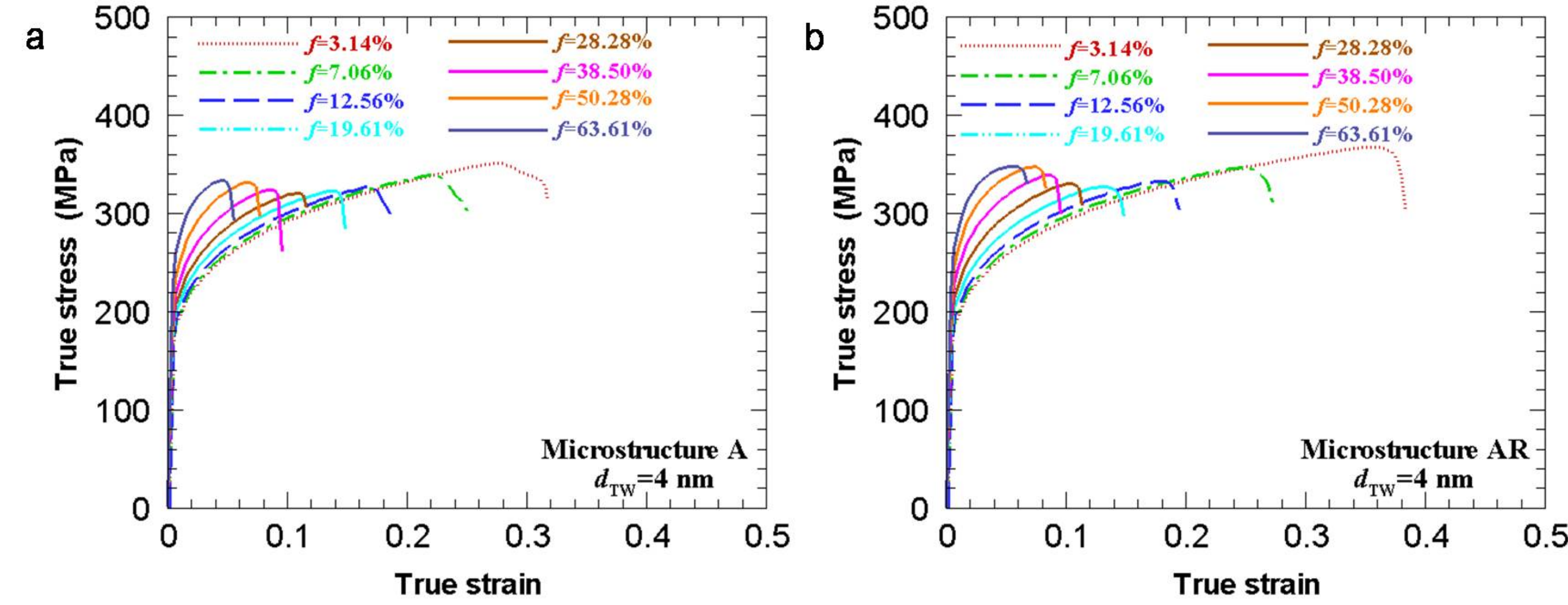

\section{Fig. 5}




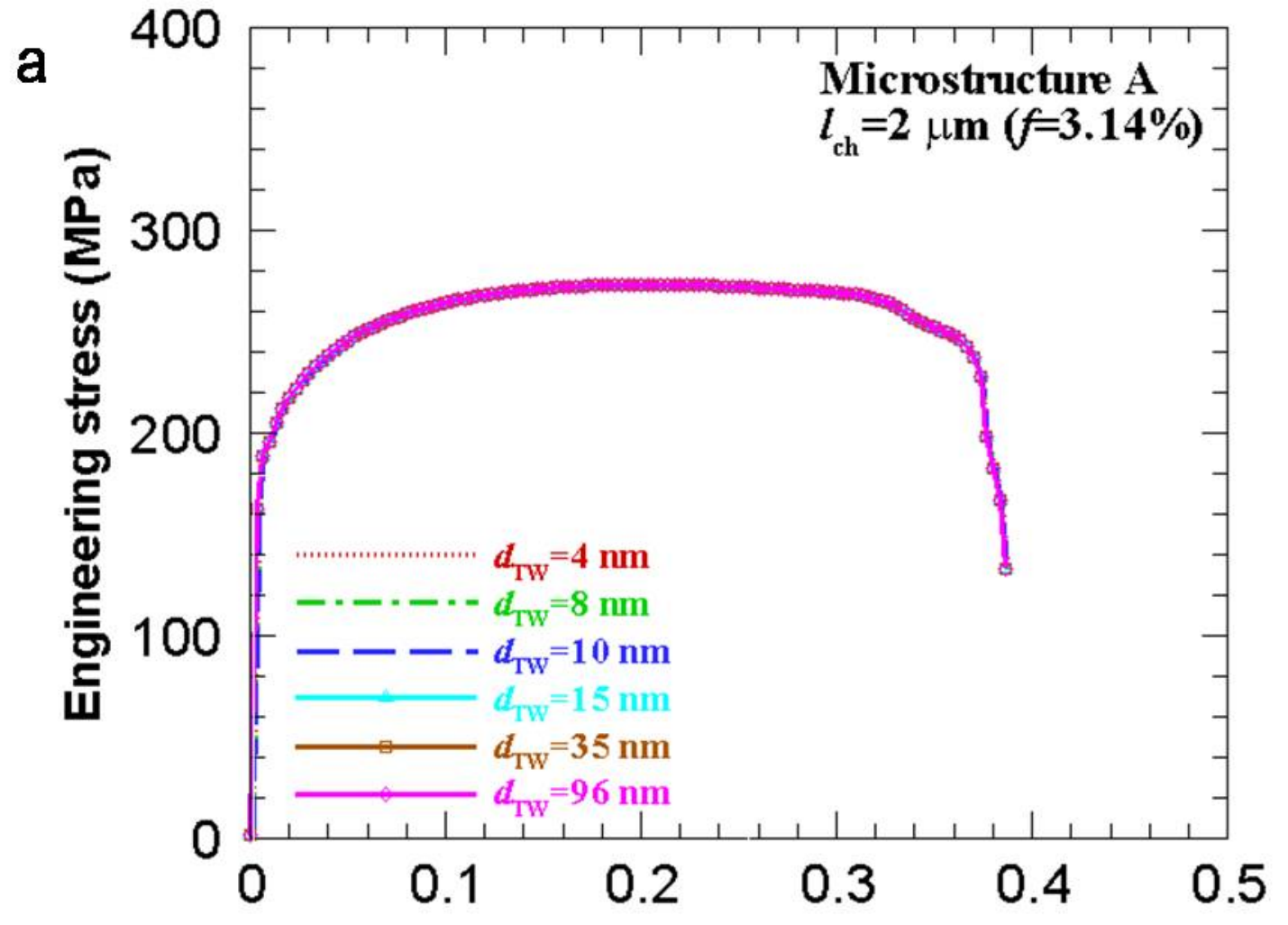

Engineering strain

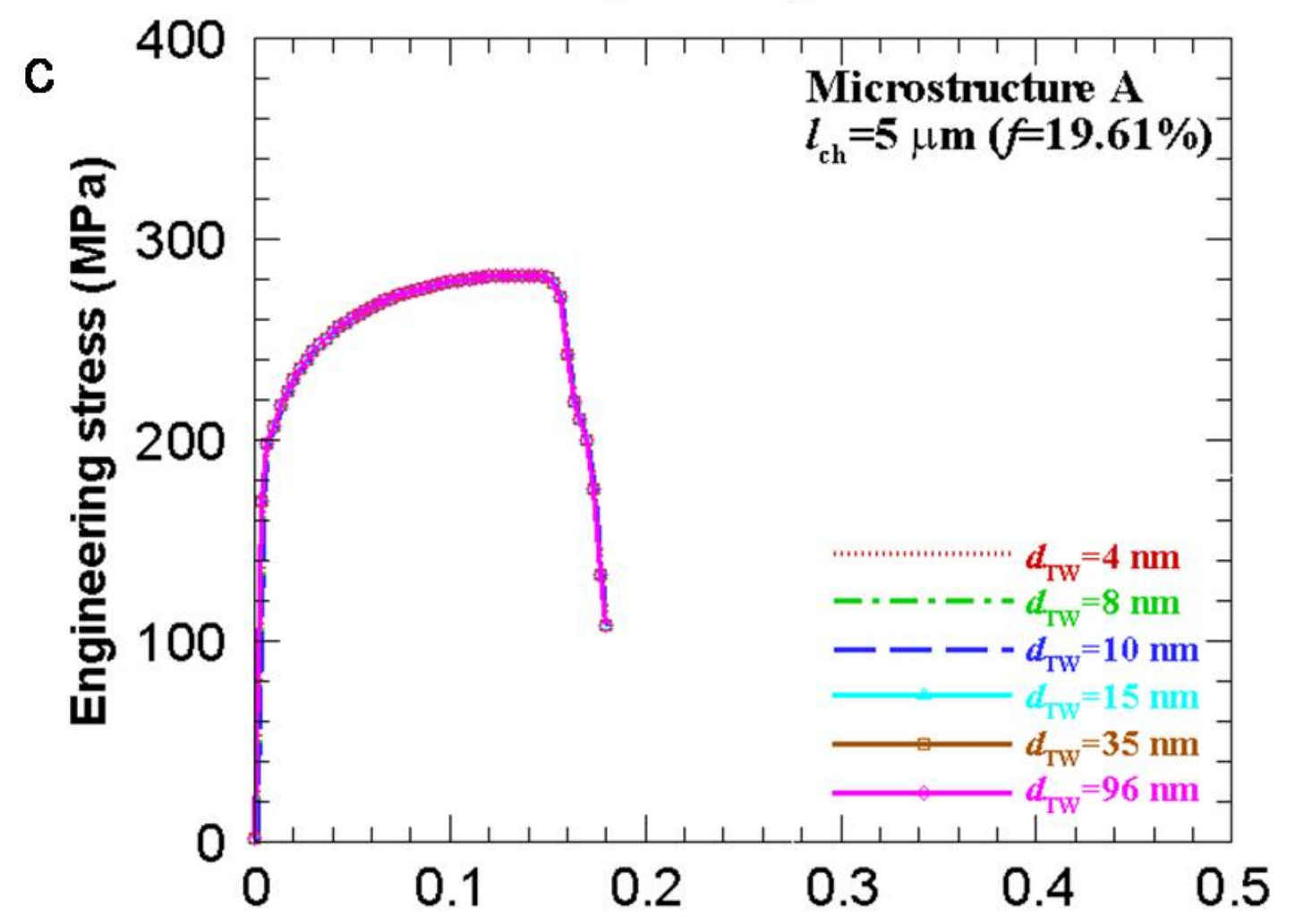

Engineering strain

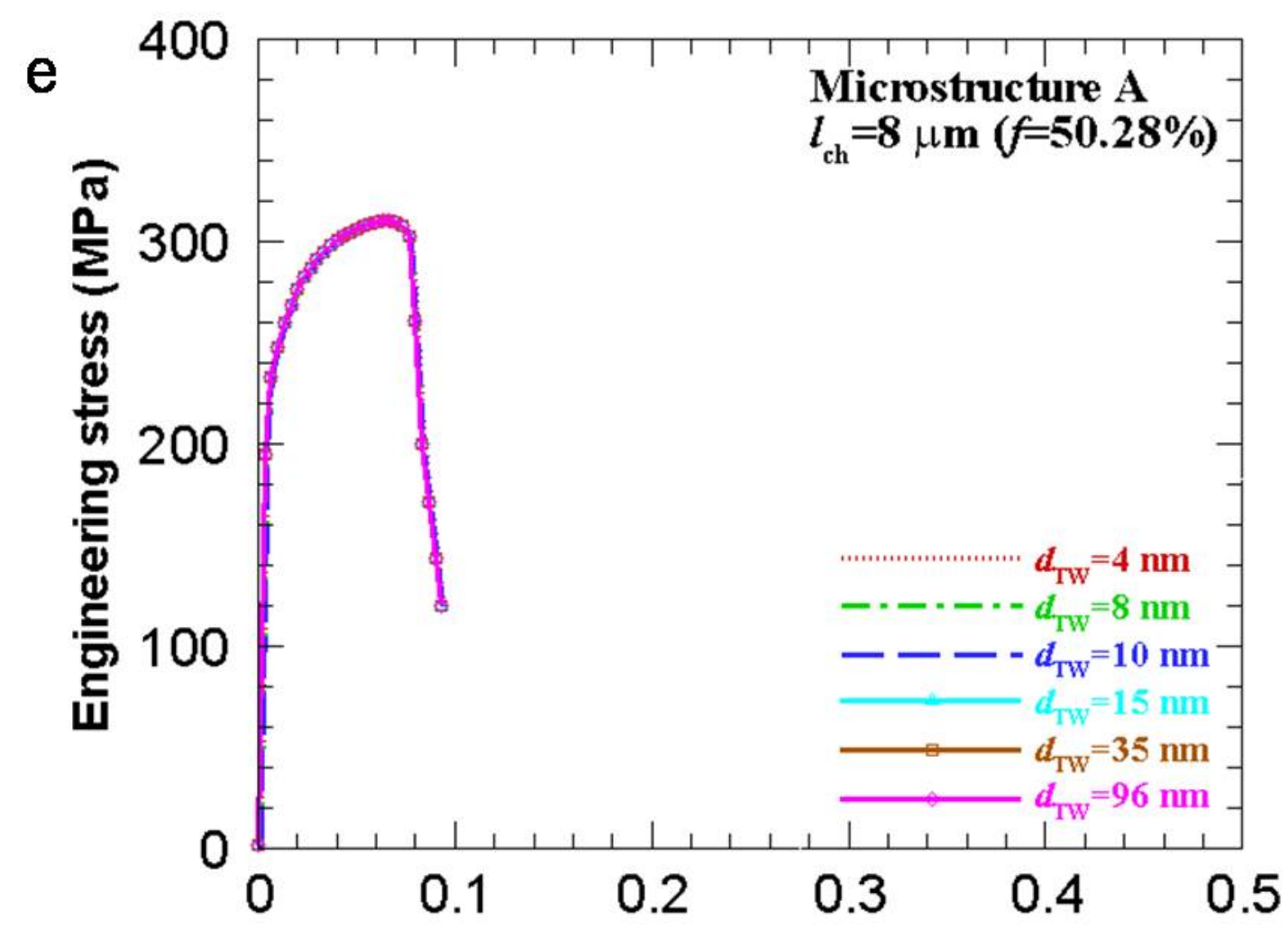

Engineering strain

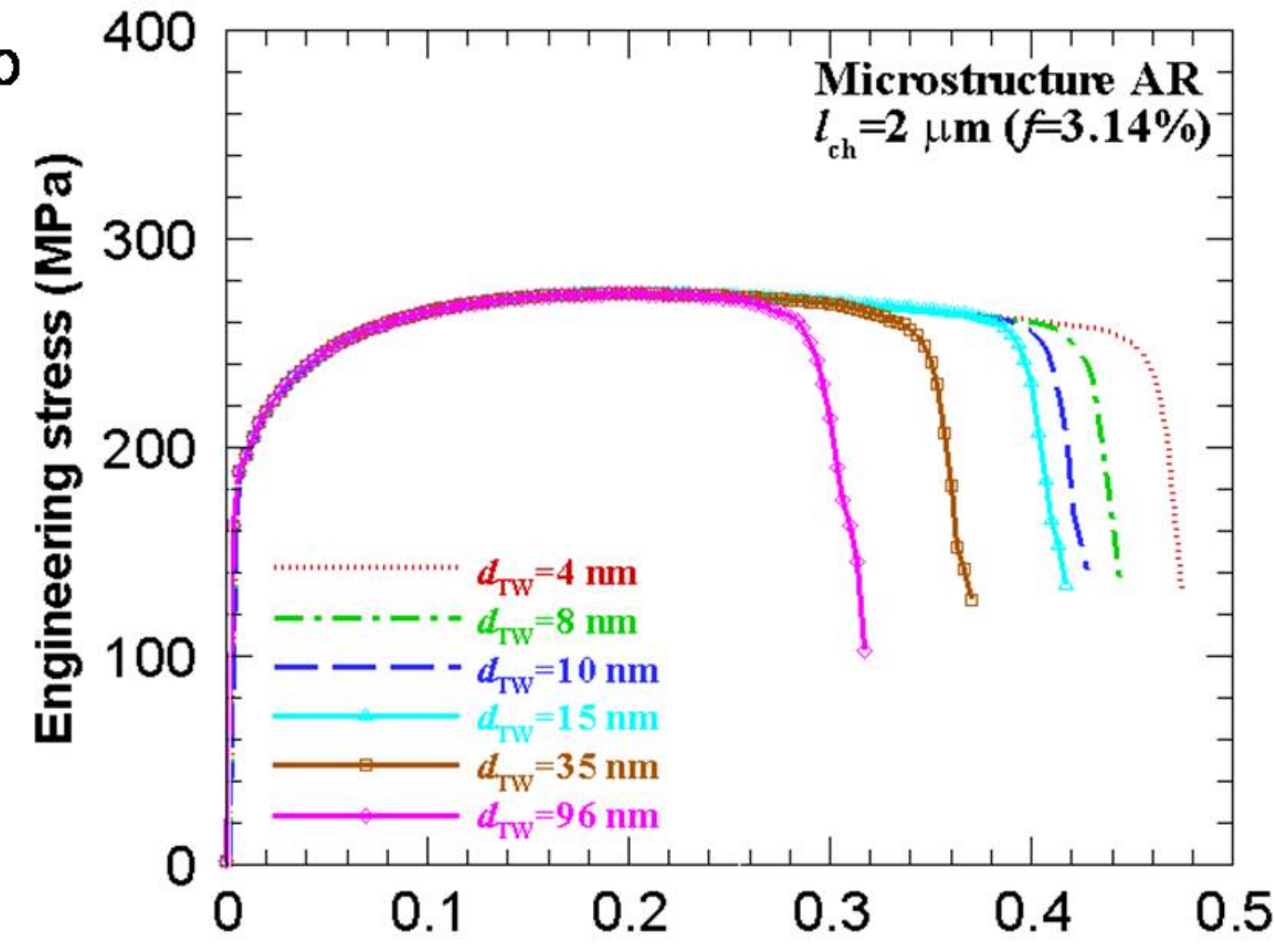

Engineering strain

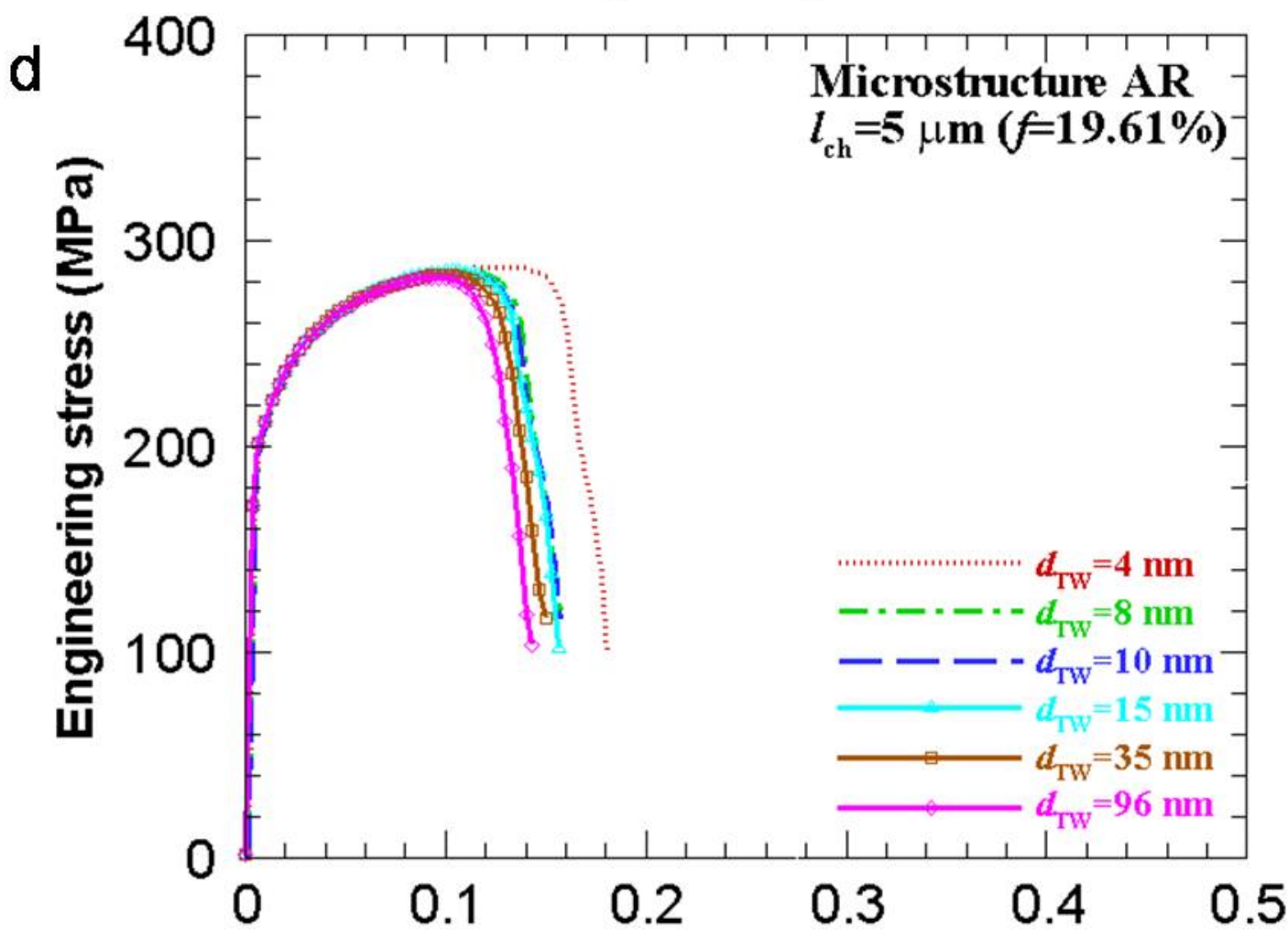

Engineering strain

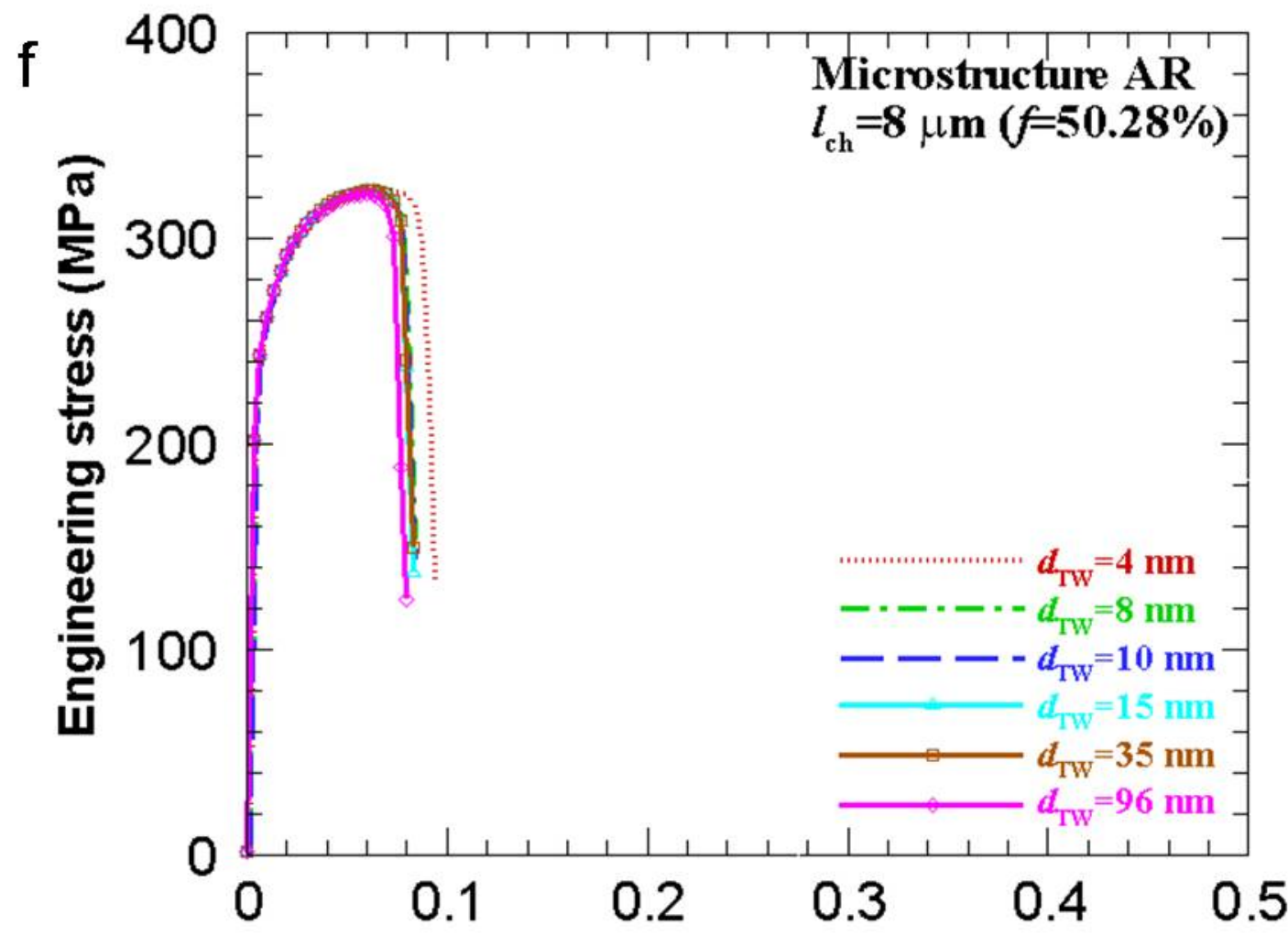

Engineering strain 


\section{a}

$\mathrm{S}$, Mises

(Avg: 75\%)

$+\quad+1.000 \mathrm{e}+09 \mathrm{~b}$

$+9.175 \mathrm{e}+08$

$+7.525 \mathrm{e}+08$

$+6.700 \mathrm{e}+08$

$+5.875 \mathrm{e}+08$

$+5.050 \mathrm{e}+08$

$+4.225 \mathrm{e}+08$

+3.400 e +08

$+2.575 \mathrm{e}+08$

+1.750 e +08

$+9.250 \mathrm{e}+07$

$+1.000 \mathrm{e}+07$

C

Fig. 9 


\section{a}

$S$, Mises

(Avg: 75\%)

T $+1.000 \mathrm{e}+09$

$+9.167 \mathrm{e}+08$

+8.335 e +08

$+7.502 \mathrm{e}+08$

$+6.670 \mathrm{e}+08$

+5.837 e +08

$+5.005 \mathrm{e}+08$

$+4.172 \mathrm{e}+08$

$+3.340 \mathrm{e}+08$

$+2.508 \mathrm{e}+08$

+1.675 e +08

+8.425 e +07

$+1.000 \mathrm{e}+06$

b

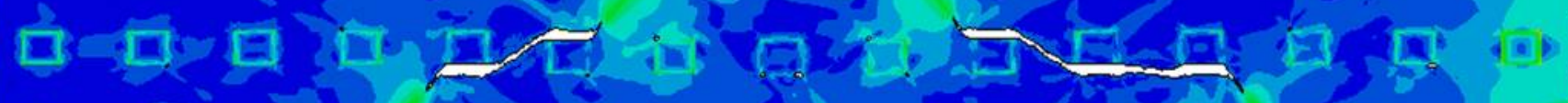

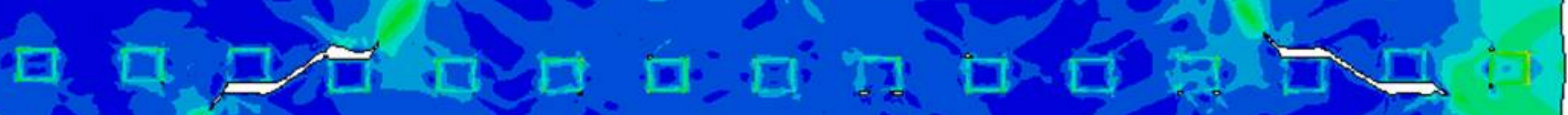

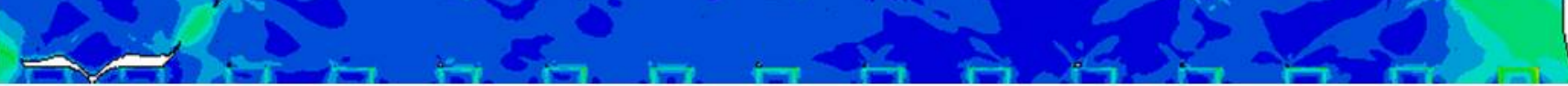

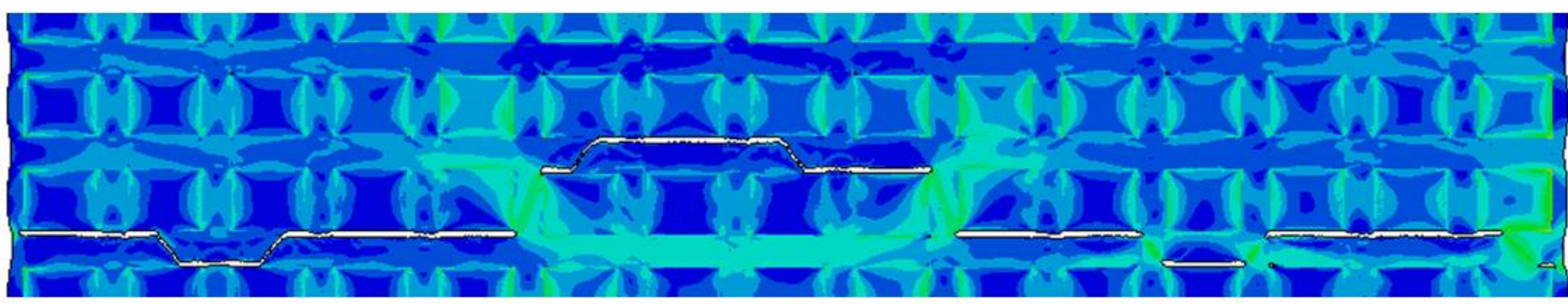

